BENÍTEZ, José Leandro Farias. A Constituição brasileira de 1988 e o conceito de Pacto Constitucional. Revista Eletrônica Direito e Política, Programa de Pós-Graduação Stricto Sensu em Ciência Jurídica da UNIVALI, Itajaí, v.13, n.2, $2^{\circ}$ quadrimestre de 2018. Disponível em: www.univali.br/direitoepolitica - ISSN 1980-7791

\title{
A CONSTITUIÇÃO BRASILEIRA DE 1988 E O CONCEITO DE PACTO CONSTITUCIONAL
}

\author{
THE BRAZILIAN CONSTITUTION AND THE CONCEPT OF CONSTITUTIONAL \\ COVENANT
}

\section{José Leandro Farias Benítez ${ }^{1}$}

SUMÁRIO: Introdução; 1 O conceito de pacto constitucional; 1.1 Poder constituinte, pacto constitucional e legitimidade; 1.2 Pacto constitucional autêntico e não autêntico; 2 A transição democrática no Brasil e a Constituição de 1988; 2.1 Os debates constitucionais na transição política; 2.2 Pacto constitucional, mas de que tipo?; Considerações finais; Referências das fontes citadas.

\begin{abstract}
RESUMO
É comum referir-se à Constituição brasileira de 1988 como resultado de um pacto constitucional. O problema que isto encerra, e que este artigo enfrenta, é se ocorreu um pacto constitucional autêntico, segundo o conceito que lhe dá Carl Schmitt. O objetivo geral é tornar precisa a menção de pacto à nossa Constituição; os objetivos específicos são o de analisar o conceito de pacto constitucional e o de analisar a questão política na nossa transição democrática. A metodologia da pesquisa do tema foi bibliográfica; o argumento central foi dedutivo. A hipótese trabalhada é a de que não ocorreu um autêntico pacto constitucional, mas sim um pacto não autêntico. Nas considerações finais se afirma que isto se deveu a várias razões: o poder constituinte foi derivado; o pacto não foi totalmente livre, não se apoiou fundamentalmente no poder constituinte do povo nem deu um novo status político a este último.
\end{abstract}

Palavras-chave: Pacto constitucional; Poder constituinte; Constituição Federal

\section{ABSTRACT}

It is common to refer to the Brazilian Constitution of 1988 as a result of a constitutional covenant. The problem of this statement, and that this paper deals with, is if this agreement was an authentic constitutional covenant, according to Carl Schmitt's concept. The general objective is to make accurate the meaning of covenant according to the Brazilian constitution; the specific objectives are to analyze the concept of constitutional covenant and the political question in the Brazilian democratic transition. The research methodology is bibliographical. The central argument is deductive. This paper hypothesis is that an authentic constitutional covenant was not achieved in Brazil, but a non-authentic one. The final considerations state that this was due to many reasons: it was a derivate constituent power; the agreement was not completely free, it was not based fundamentally on people's constituent power and it has not given a new political status to citizens.

Keywords: Constitutional covenant; Constituent power; Brazilian constitution.

\footnotetext{
${ }^{1}$ Doutorando Mestre e em Direito pela UFSC. Professor da UNIVALI no campus Balneário Camboriú. Endereço eletrônico: jlfbenitez@hotmail.com
} 
BENÍTEZ, José Leandro Farias. A Constituição brasileira de 1988 e o conceito de Pacto Constitucional. Revista Eletrônica Direito e Política, Programa de Pós-Graduação Stricto Sensu em Ciência Jurídica da UNIVALI, Itajaí, v.13, n.2, $2^{\circ}$ quadrimestre de 2018. Disponível em: www.univali.br/direitoepolitica - ISSN 1980-7791

\section{INTRODUÇÃO}

Por todas as razões a Constituição de 1988 é um marco na legislação brasileira, não apenas por ser a lei atual, mas por inaugurar um dos períodos mais importantes da história do país nas questões de duração e efetividade democráticas. Ela marca o fim da transição política de um regime autoritário posterior à quebra de um regime constitucional. Os estudos dessa recente história política e constitucional do Brasil são bastante sólidos e abundantes neste ponto. A nossa lei maior está próxima de completar trinta anos. Esta é uma duração suficiente para compreendê-la de modo devido, podendo-se então estimar as suas perspectivas de futuro, especialmente face à preocupante situação política que o país atravessa.

A referência a constituição como pacto é bastante comum porque muitas delas merecem levar esta qualificação. Porém o conceito de pacto que se utiliza não é frequentemente bem explicitado nem é volumosamente tratado na literatura jurídica brasileira. Uma tentativa de melhor compreensão deve começar por um correto enquadramento da nossa Constituição dentro das várias possibilidades que apresentam os conceitos constitucionais. Apresenta-se então o objetivo geral deste artigo: analisar se é adequado o conceito de pacto constitucional à Constituição brasileira de 1988. O problema que será enfrentado é a indagação se esta lei teve origem no chamado pacto constitucional autêntico, de acordo com o respectivo conceito que Ihe dá Carl Schmitt. A hipótese sobre a qual se trabalhará é a de que não se deu um pacto autêntico, mas um não autêntico. Para isso se recorrerá a uma pesquisa bibliográfica sobre o conceito de pacto constitucional e sobre a história da Constituição brasileira de 1988. Utilizar-se-á o método dedutivo, partindo do conceito geral de pacto constitucional, para se buscar a conclusão particular sobre a sua ocorrência ou não no Brasil. O objetivo geral é tornar precisa a menção de pacto à nossa Constituição; os objetivos específicos são o de analisar o conceito de pacto constitucional e o de analisar a questão política na nossa transição democrática. 
BENÍTEZ, José Leandro Farias. A Constituição brasileira de 1988 e o conceito de Pacto Constitucional. Revista Eletrônica Direito e Política, Programa de Pós-Graduação Stricto Sensu em Ciência Jurídica da UNIVALI, Itajaí, v.13, n.2, $2^{\circ}$ quadrimestre de 2018. Disponível em: www.univali.br/direitoepolitica - ISSN 1980-7791

\section{O CONCEITO DE PACTO CONSTITUCIONAL}

Quando um autor importante como Lassalle refere, no início de sua obra, ao possível conceito de constituição dado por um jurista, como sendo "um pacto juramentado entre o rei e o povo", abre-se o leque de uma gama de significados que precisam ser objeto de análise. Mesmo dentro da filosofia política a noção de pacto costuma ser igualada entre autores distantes como Marsílio de Pádua e Rousseau. Ao se enfrentar esse tema dentro da teoria constitucional é indispensável recorrer, em primeira mão e decididamente, a Carl Schmitt e sua Teoria da constituição, aquela que é sem muita disputa a obra mais importante do século XX dentro da teoria constitucional.

A constituição de Massachussets, escrita por John Adams e aprovada em 1780, foi uma das cinquenta constituições estatais que contribuíram para conformar o governo dos Estados Unidos da América. Ela diz, no preâmbulo, que a unidade política surge da união voluntária dos indivíduos, a qual resulta de um pacto social mediante o qual a totalidade do povo contrata com cada cidadão e vice-versa, para estes serem regidos por leis no interesse geral. É isto um pacto constitucional? Lassalle também empregou o termo com o mesmo significado?

A palavra pacto tem muitos sentidos. Quando um autor medieval funda o estado ou o governo num pacto; um filósofo do século XVII, como Hobbes, usa a palavra; e no século XX um jurista defende que o estado democrático-parlamentar descansa num compromisso, se contrapõem ideias que podem ser muito diferentes, de modo que é necessário fazer desde já uma distinção, sob pena de se imaginar que o estado moderno se assenta no princípio, oriundo do pretor romano, de que pacta sunt servanda, o que não é o caso. A palavra pacto vem do latim pactus, que significa pacto, acordo, a qual por sua vez provém do verbo pasciscor (= pactuar, ajustar). Os pactos se tornaram fontes de obrigações, e Ulpiano os definia como "o acordo e consentimento de duas ou mais pessoas em uma mesma coisa" (Digesto 2, 14, 1, 2). Isto já anuncia um elemento do termo, que é o enfrentamento de duas pessoas ou partes. No direito romano antigo os pactos não tinham eficácia processual e davam origem apenas a obrigações naturais. Então o pretor passou a proteger os pactos, inicialmente outorgando uma exceção se una parte fosse demandada contrariamente ao que se houvesse acordado. A seguir, em seu edito, o pretor estabeleceu: "Manterei os pactos 
BENÍTEZ, José Leandro Farias. A Constituição brasileira de 1988 e o conceito de Pacto Constitucional. Revista Eletrônica Direito e Política, Programa de Pós-Graduação Stricto Sensu em Ciência Jurídica da UNIVALI, Itajaí, v.13, n.2, $2^{\circ}$ quadrimestre de 2018. Disponível em: www.univali.br/direitoepolitica - ISSN 1980-7791

convindos que se tenham feito sem dolo, sem infringir as leis, plebiscitos, senadoconsultos, decretos e editos dos imperadores, e que não sejam feitos em fraude a quaisquer dos mesmos" (Ulpiano, Digesto 2, 14, 7, 7). Desde lá é que a expressão pacta sunt servanda passa a ter sentido, pois antes do edito do pretor não era claro que alguém pudesse se obrigar por pacta. Na Idade Média foram fixados, por escrito, convênios entre o príncipe e seus vassalos ou estamentos, que se denominaram cartas, cujo exemplo mais famoso é a Magna Carta, de 1215. No entanto estas cartas eram convenções bilaterais, que afirmavam privilégios aos barões mediante contraprestações de parte destes. O que se dava na época era algo diferente do que seja uma moderna constituição escrita. Este tipo de convênio os historiadores chamam de acordos de governo (compacts of government ou Herrschaftsverträge). Em síntese, são acordos entre o rei e alguns de seus súditos, especialmente a aristocracia, quanto ao exercício do poder real, mediante o estabelecimento de privilegia ou libertates a certos sujeitos ${ }^{2}$. Essas estipulações medievais entre príncipe e senhores feudais eram bastante comuns na época, e sua natureza jurídica foi objeto de discussões. Alguns a consideram lei porque foi dada pelo rei; outros a consideram um contrato de direito público; outros um contrato de direito privado; uma lei constitucional com uma declaração de direitos ou então um pacto entre o príncipe e o povo. Mas no fundo é incorreto considerar essas estipulações uma constituição, pois não se podem transportar conceitos do medievo ao moderno direito político. Segundo Carl Schmitt o objeto das constituições modernas é a forma de existência da unidade política, e esta não era objeto daquelas estipulações. Elas não fundavam nenhuma unidade política; ao contrário, eram estipulações referentes à dissolução de uma unidade política anteriormente existente ${ }^{3}$.

Também é fundamental estabelecer a noção de pacto ou contrato social, presente na obra dos autores integrantes do chamado contratualismo, entendido este como "uma teoria totalizadora sobre as origens da sociedade e sua evolução para formas

2 PASQUINO, Pasquale. Classifying constitutions: preliminary conceptual analysis. Cardozo Law Review. New York, volume 34, número 3, p. 1008, fevereiro 2013. Disponível em: http://www.cardozolawreview.com/content/34-3/PASQUINO.34.3.pdf. Acesso em: 23 de junho de 2017.

3 SCHMITT, Carl. Teoría de la constitución. Tradução de Francisco Ayala. Madrid: Alianza, 1996, p. 67 
BENÍTEZ, José Leandro Farias. A Constituição brasileira de 1988 e o conceito de Pacto Constitucional. Revista Eletrônica Direito e Política, Programa de Pós-Graduação Stricto Sensu em Ciência Jurídica da UNIVALI, Itajaí, v.13, n.2, $2^{\circ}$ quadrimestre de 2018. Disponível em: www.univali.br/direitoepolitica - ISSN 1980-7791

políticas avançadas"4. Rousseau e demais autores contratualistas veem o contrato social como o ato fundador de um estado. Neste ponto Carl Schmitt distingue contrato social de pacto constitucional, este considerado o ato instituidor de uma constituição. Tal diferença já estava presente em Rousseau quando, no livro II, capítulo XII de O contrato social, estabeleceu a distinção entre contrato social que funda o estado- e as leis políticas ou fundamentais, que regulam o exercício do poder do estado 5 . Schmitt sustenta que contrato social não é igual a constituição em sentido positivo, e aquele já está suposto na doutrina do poder constituinte do povo, conforme se verá abaixo ${ }^{6}$. Uma perspectiva diferente e menos decantada, que não se considerará neste artigo, junta as noções de pacto social e pacto constitucional, e é adotada por um ou outro autor?

\subsection{PODER CONSTITUINTE, PACTO CONSTITUCIONAL E LEGITIMIDADE}

Naturalmente o conceito de pacto constitucional está assentado no conceito de poder constituinte. A constituição é a criatura de um criador superior, que os Pais Fundadores norte-americanos do século XVIII chamaram de poder constituinte e cuja teoria foi desenvolvida pioneiramente por Sieyès em sua obra $O$ que é o Terceiro estado?

Para Schmitt, poder constituinte é a vontade política dotada de força para determinar o modo e a forma da própria existência política ${ }^{8}$. Diz ele que a constituição não surge de si mesma, não se dá a si mesma, mas por uma unidade política concreta. A normatização jurídica e a constituição pressupõem tal vontade como existente. Toda lei, inclusive a constituição, precisam, para sua validade última, de uma decisão política prévia, adotada por um poder ou autoridade

4 DI TELLA, Torcuato (organizador). Diccionario de ciencias sociales y políticas. Buenos Aires: Emecé, 2001, p. 125

5 SCHMITT, Carl. Teoría de la constitución, p. 81 e 46

${ }^{6}$ SCHMITT, Carl. Teoría de la constitución, p. 46, 80 e 81

7 Por exemplo: COSTA GONÇALVES, Cláudia Maria da. Pacto constitucional e welfare state: anotações de sociologia constitucional brasileira. Revista de Políticas Públicas. São Luís: volume 10, número 1, páginas 91-107, janeiro-junho 2006. Disponível em: http://www.periodicoseletronicos.ufma.br/index.php/rppublica/article/view/3794/1893. Acesso em: 23 de junho de 2017

8 SCHMITT, Carl. Teoría de la constitución, p. 93 
BENÍTEZ, José Leandro Farias. A Constituição brasileira de 1988 e o conceito de Pacto Constitucional. Revista Eletrônica Direito e Política, Programa de Pós-Graduação Stricto Sensu em Ciência Jurídica da UNIVALI, Itajaí, v.13, n.2, 20 quadrimestre de 2018. Disponível em: www.univali.br/direitoepolitica - ISSN 1980-7791

politicamente existente. O que existe como magnitude política é juridicamente considerável, digno de existência ${ }^{9}$. Essa ideia de unidade, tão cara à obra desse autor, provém de alguns fatos políticos nos quais aquela foi constatada, como no momento em que veio à luz a constituição de Massachussets, a qual afirmava que o pacto social é resultado da contratação da "totalidade do povo", sendo que aqui a totalidade de cidadãos está suposta como unidade política ${ }^{10}$. Outro fato foi a Revolução Francesa, que foi ponto de partida da unidade política do povo francês. A constituição francesa não foi assim um pacto entre o príncipe e o povo, mas uma decisão una e indivisível adotada pela nação para fixar o seu destino. Por outro lado, se várias unidades políticas e sujeitos independentes do poder constituinte adotam em comum, por si mesmos, uma decisão semelhante, que fixa um status político em concorrência, então se tem uma constituição pactuada ou acordada11.

É de um a ato do poder constituinte que surge a constituição em sentido positivo (constituição como decisão de conjunto sobre o modo e forma da unidade política). $\mathrm{O}$ ato constituinte não contém quaisquer normas, mas, por ser um único momento de decisão, contém a totalidade da unidade política considerada. Este ato constitui a forma e o modo da unidade política, cuja existência é anterior. Não sucede que a unidade política surja porque se tenha dado uma constituição. Sempre há no ato constituinte um sujeito capaz de obrar, que o realiza com a vontade de dar uma constituição. Tal constituição é uma decisão consciente que a unidade política, através do titular do poder constituinte, adota para si mesma e se dá a si mesma ${ }^{12}$. A vontade política emanada daquele que dá a constituição é manifestação de um poder constituinte. Uma constituição nasce então mediante uma decisão política unilateral do sujeito do poder constituinte ou mediante uma convenção plurilateral dos vários sujeitos do poder constituinte ${ }^{13}$. Em toda normatização existe uma

\footnotetext{
${ }^{9}$ SCHMITT, Carl. Teoría de la constitución, p. 46

${ }^{10}$ SCHMITT, Carl. Teoría de la constitución, p. 81

${ }^{11}$ SCHMITT, Carl. Teoría de la constitución, p. 66

12 SCHMITT, Carl. Teoría de la constitución, p. 45

${ }^{13}$ SCHMITT, Carl. Teoría de la constitución, p. 66
} 
BENÍTEZ, José Leandro Farias. A Constituição brasileira de 1988 e o conceito de Pacto Constitucional. Revista Eletrônica Direito e Política, Programa de Pós-Graduação Stricto Sensu em Ciência Jurídica da UNIVALI, Itajaí, v.13, n.2, 20 quadrimestre de 2018. Disponível em: www.univali.br/direitoepolitica - ISSN 1980-7791

decisão política do titular do poder constituinte, ou seja: do povo, na democracia; e do monarca, na monarquia autêntica ${ }^{14}$.

Do conceito de poder constituinte deriva a ideia de legitimidade de uma constituição. Há duas classes de legitimidade: a dinástica e a democrática, que correspondem aos dois sujeitos do poder constituinte que há que se considerar: o príncipe e o povo. Onde prepondera a autoridade, se reconhece o poder constituinte do rei; onde impera a maioria do povo, a constituição se assenta na vontade do povo. Só se pode falar de legitimidade de uma constituição a partir de razões históricas, e sempre sob o ponto de vista da distinção entre legitimidade dinástica e democrática ${ }^{15}$. Em suma a constituição se apoia ou no princípio monárquico, ou no democrático; ou no poder constituinte do príncipe ou no do povo ${ }^{16}$. Por decorrência, no processo de formação de monarquias constitucionais, como por exemplo na Restauração francesa, o advento das constituições se deu de maneira não verdadeiramente democrática. Como resultado do princípio monárquico, dava-se que o rei, por seu poder, emitia uma constituição, isto é, adotava a decisão política fundamental e unilateral porque era sujeito do poder constituinte. Então a constituição não era um pacto, mas uma lei emitida pelo rei. A plenitude do poder do estado permanecia com o soberano, apesar da constituição. Em monarquias politicamente fortes as constituições surgiram sob este princípio monárquico. Não eram pactuadas com a representação popular, mas outorgadas. E quando eram pactuadas, não decaía o princípio monárquico e não se reconhecia o poder constituinte do povo ${ }^{17}$.

As exigências de uma constituição escrita fazem que ela seja considerada uma lei. Ainda que tenha se erigido como convênio entre o príncipe e a representação popular, ela só pode ser mudada pela via legislativa. A partir de então os conceitos

\footnotetext{
${ }^{14}$ SCHMITT, Carl. Teoría de la constitución, p. 47 e 66

${ }^{15}$ SCHMITT, Carl. Teoría de la constitución, p. 104

${ }^{16}$ SCHMITT, Carl. Teoría de la constitución, p. 74

17 SCHMITT, Carl. Teoría de la constitución, p. 73
} 
BENÍTEZ, José Leandro Farias. A Constituição brasileira de 1988 e o conceito de Pacto Constitucional. Revista Eletrônica Direito e Política, Programa de Pós-Graduação Stricto Sensu em Ciência Jurídica da UNIVALI, Itajaí, v.13, n.2, $2^{\circ}$ quadrimestre de 2018. Disponível em: www.univali.br/direitoepolitica - ISSN 1980-7791

pacto e lei só assumem o sentido político de assegurar a cooperação da representação popular ${ }^{18}$.

Finalmente, a base jurídica de um pacto constitucional não é o preceito geral pacta sunt servanda; nem é este um preceito constitucional; nem uma comunidade pode se fundar neste preceito, pois a ele não é inerente à ideia de unidade ${ }^{19}$.

Neste ponto há que se fazer uma digressão e frisar que a referência a povo, fundamental na obra de Schmitt, é de compreensão bastante delicada por uma série de razões. Holmes diz que se deve estar atento ao "misticismo democrático de Schmitt", pois não há sentido em falar de governo popular se não houver algum marco legal que permita ao eleitorado ter uma vontade manifestada e coerente ${ }^{20}$. Cicero Araujo diz que, embora o conceito de poder constituinte seja de origem democrática, cedo surgiram no constitucionalismo interpretações que ele qualifica de autoritário-conservadoras do poder constituinte, como a de Carl Schmitt. Ao falar em povo, as correntes autoritárias obteriam legitimidade apenas para seus primeiros passos, mas acabaram por reduzir mais tarde o povo a um ente compacto e manobrável ${ }^{21}$. Por último, de acordo com Pasquino, há que fazer uma precisão ao se referir ao povo como sujeito do poder constituinte. Não se deve fundir o conceito de autoria com autorização. O povo, enquanto membro de uma comunidade política, nunca é autor de uma constituição, apenas autoriza ex post o texto diretamente (através de referendo) ou indiretamente (através de representantes). O texto é preparado por peritos legais e apoiado por uma maioria política (quando a constituição não é outorgada aos cidadãos a partir de um golpe de estado $)^{22}$. Além destes alertas, que são inseparáveis de qualquer leitura correta

\footnotetext{
18 SCHMITT, Carl. Teoría de la constitución, p. 39

19 SCHMITT, Carl. Teoría de la constitución, p. 87

20 HOLMES, Stephen. El precompromiso y la paradoja de la democracia. In: ELSTER, Jon e SLAGSTAD, Rune (organizadores). Constitucionalismo y democracia. México: Fondo de Cultura Económica, 1999, p. 246
}

${ }^{21}$ ARAUJO, Cicero. O processo constituinte brasileiro, a transição e o Poder Constituinte. Lua Nova. São Paulo, número 88, 2013, p. 372. Disponível em: http://www.cedec.org.br/constituicao-eprocesso-constituinte---no88---ano-2013. Acesso em: 23 de junho de 2017

22 PASQUINO, Pasquale. Classifying constitutions: preliminary conceptual analysis. Cardozo Law Review, p. 1004 
BENÍTEZ, José Leandro Farias. A Constituição brasileira de 1988 e o conceito de Pacto Constitucional. Revista Eletrônica Direito e Política, Programa de Pós-Graduação Stricto Sensu em Ciência Jurídica da UNIVALI, Itajaí, v.13, n.2, 20 quadrimestre de 2018. Disponível em: www.univali.br/direitoepolitica - ISSN 1980-7791

de teoria constitucional -especialmente da de Schmitt-, há que considerar a advertência de Waldron quanto aos chamados "constitucionalismo popular" ou "constitucionalismo democrático", aos quais se exige que construam uma teoria constitucional madura, capaz de evitar o sentimento popular de que o mesmo documento que se supõe dê poderes ao povo, na realidade Ihes suprima ${ }^{23}$.

\subsection{PACTO CONSTITUCIONAL AUTÊNTICO E NÃO AUTÊNTICO}

Um pacto constitucional não funda a unidade política, e sim a pressupõe. Não é o covenant (do verbo to covenant, constante no preâmbulo da mencionada constituição de Massachussets) sobre o qual a comunidade descansa, mas um pacto de governo entendido em sua atuação total organizada 24 .

O pacto constitucional dentro de uma unidade política se explica pelo dualismo entre monarquia constitucional e o povo. É um simples dilema: príncipe ou povo; povo como unidade política capaz do obrar; príncipe como representante da unidade política. Numa unidade política só cabe dar uma constituição, não pactuála, porque para que haja uma convenção constitucional há que existirem várias unidades políticas. Quando uma constituição é outorgada unilateralmente pelo príncipe ela não é pactuada ${ }^{25}$. Este contraste entre o princípio monárquico e o princípio democrático afeta o poder constituinte - ou seja, as decisões políticas concretas relativas à forma de existência da unidade política. Aqui são possíveis "compromissos dilatórios, isto é, adiamentos e suspensões da decisão, mas não um compromisso objetivo que possa transformar em um resultado harmônico o dilema ineludível"26. Ainda segundo esse autor, se uma constituição houvesse sido emitida unilateralmente pelo príncipe (outorgada), ela se assentaria no poder constituinte do príncipe. Se se impedisse por razões políticas a outorga, e se pactuasse a constituição entre príncipe e representação popular, então haveria um

\footnotetext{
23 WALDRON, Jeremy. Constitutionalism: a skeptical view. Public \& Legal Theory Research Paper Series. New York: número 10-87, 2012, p. 28. Disponível em: https://papers.ssrn.com/sol3/papers.cfm?abstract_id=1722771. Acesso em: 23 de junho de 2017

${ }^{24}$ SCHMITT, Carl. Teoría de la constitución, p. 81

25 SCHMITT, Carl. Teoría de la constitución, p. 82

${ }^{26}$ SCHMITT, Carl. Teoría de la constitución, p. 85
} 
BENÍTEZ, José Leandro Farias. A Constituição brasileira de 1988 e o conceito de Pacto Constitucional. Revista Eletrônica Direito e Política, Programa de Pós-Graduação Stricto Sensu em Ciência Jurídica da UNIVALI, Itajaí, v.13, n.2, 20 quadrimestre de 2018. Disponível em: www.univali.br/direitoepolitica - ISSN 1980-7791

compromisso dilatório enquanto o príncipe não renunciasse expressamente a seu poder constituinte e reconhecesse em seu lugar o fundamento democrático: o poder constituinte do povo. Schmitt sustenta que nas monarquias da Alemanha nunca tinha havido um reconhecimento do princípio democrático, pois as várias convenções constitucionais alemãs do século XIX não resolviam a questão do sujeito do poder constituinte. Elas significavam um compromisso que deixava sem decidir esse conflito ${ }^{27}$. Então persistiam duas contradições. Primeira: as constituições da época eram um pacto, pois não eram outorgadas, porém um pacto entre príncipe e representação nacional. Segunda: as constituições eram leis, porque estas supõem a cooperação e anuência da representação popular ${ }^{28}$.

Um autêntico pacto constitucional supõe duas partes, cada uma sendo sujeito de um poder constituinte, o que faz desse pacto uma unidade política. É um pacto federal, e com ele surge uma nova constituição ${ }^{29}$. Ele é sempre um pacto de status e dá um novo status para aqueles que participaram do acordo. É um pacto livre porque descansa na vontade dos sujeitos concorrentes. Não é pacto livre no sentido jusprivatista de contrato ou de uma ordenação social liberal-burguesa apoiada na liberdade contratual ${ }^{30}$. O autêntico pacto constitucional supõe como partes do contrato várias unidades políticas, que têm um status enquanto tal. Com ele se funda um novo status para todos os estados que participam do acordo.

Uma constituição baseada no poder constituinte do povo é diferente de um pacto social. O princípio democrático do poder constituinte exige que a constituição surja mediante um ato do povo politicamente capacitado. O povo tem que existir e ser suposto como unidade política se for o sujeito de um poder constituinte. Ao contrário, as construções de um contrato social ou de estado servem para fundar

\footnotetext{
27 SCHMITT, Carl. Teoría de la constitución, p. 74 e 82

${ }^{28}$ SCHMITT, Carl. Teoría de la constitución, p. 82

${ }^{29}$ SCHMITT, Carl. Teoría de la constitución, p. 82

${ }^{30}$ SCHMITT, Carl. Teoría de la constitución, p. 85
} 
BENÍTEZ, José Leandro Farias. A Constituição brasileira de 1988 e o conceito de Pacto Constitucional. Revista Eletrônica Direito e Política, Programa de Pós-Graduação Stricto Sensu em Ciência Jurídica da UNIVALI, Itajaí, v.13, n.2, $2^{\circ}$ quadrimestre de 2018. Disponível em: www.univali.br/direitoepolitica - ISSN 1980-7791

a unidade política do povo ${ }^{31}$. O contrato social já está suposto na doutrina do poder constituinte do povo ${ }^{32}$.

Diz Schmitt que na fundação da federação norte-americana e na do império alemão (II Reich, após a unificação da Alemanha promovida por Bismarck) teve lugar um autêntico convênio constitucional ${ }^{33}$. Alguns anos antes de se consolidar a unificação alemã, naturalmente já não tinha sentido explicar a situação constitucional daquele país com base nas ideias medievais de pactos estamentais, e sim de que uma constituição pactuada era uma constituição não outorgada, decorrente de um compromisso não autêntico. No entanto não se podia falar de poder constituinte do povo alemão; no máximo se tratava de um reconhecimento pouco claro e parcial do poder constituinte do povo e, com ele, do princípio democrático ${ }^{34}$. Segundo Schmitt, finalmente a constituição de Weimar, de 1919, resultou de ato do poder constituinte do povo: "O especificamente democrático da constituição consiste em que não é o rei, mas o povo, quem exercita o poder constituinte" 35 .

\section{A transição democrática no Brasil e a Constituição de 1988}

Em um de seus estudos Przeworski afirma que, durante quase toda a história conhecida, a ordem foi mantida pelo uso da força. Trocas pacíficas de governos têm sido raras: entre 1788 e 1975, uma entre seis eleições nacionais resultaram na derrota do governo no cargo, e uma em sete resultaram em alternância pacífica no poder ${ }^{36}$. Derrotas de governos têm sido incomuns porque aqueles usam o aparato estatal para abalar a condição do outro, o que propicia golpes e guerras

\footnotetext{
${ }^{31}$ SCHMITT, Carl. Teoría de la constitución, p. 80

32 SCHMITT, Carl. Teoría de la constitución, p. 80

33 SCHMITT, Carl. Teoría de la constitución, p. 83

${ }^{34}$ SCHMITT, Carl. Teoría de la constitución, p. 83

35 SCHMITT, Carl. Teoría de la constitución, p. 49
}

36 PRZEWORSKI, Adam. Divided we stand? Democracy as a method of processing conflicts. Scandinavian Political Studies. United Kingdom: volume 34, número 2, 2011, p. 169. Disponível em: https://onlinelibrary.wiley.com/doi/pdf/10.1111/j.1467-9477.2011.00265.x. Acesso em: 23 de junho de 2017 
BENÍTEZ, José Leandro Farias. A Constituição brasileira de 1988 e o conceito de Pacto Constitucional. Revista Eletrônica Direito e Política, Programa de Pós-Graduação Stricto Sensu em Ciência Jurídica da UNIVALI, Itajaí, v.13, n.2, $2^{\circ}$ quadrimestre de 2018. Disponível em: www.univali.br/direitoepolitica - ISSN 1980-7791

civis $^{37}$. Afirma ele também que golpes de estado e guerras civis tendem a ser menos frequentes em países de renda per capita elevada ${ }^{38}$. Complôs tenderiam a aumentar quando um governo democrático não é efetivo ou quando a legislatura é subserviente. Em países pobres as instituições políticas importam menos que nos países ricos. Naqueles países as instituições têm que conceder poderes a forças extra-institucionais (especialmente militares) de modo a tornar atrativa a sua permanência dentro do arcabouço institucional ${ }^{39}$. Para além dessas tendências, certamente um fator decisivo na implantação de regimes autoritários na América Latina, a partir da década de 60, foi a ação norte-americana para preservar as suas áreas de influência durante a Guerra Fria.

Apesar de que possa existir ainda algum debatedor saudoso ou surdo, há uma abundante produção acadêmica, no ramo da história, a sustentar que o que ocorreu no Brasil, em abril de 1964, foi um Putsch clássico. Até 1967 foi um regime político "incompletamente autoritário"; já no fim dos anos 60 se se tornou "abertamente ditatorial"40. O regime foi o produto de um conluio entre a elite civil e a hierarquia militar, a qual julgou encarnar o espírito do povo. Desde o princípio os militares tentaram colocar em prática governos algo representativos e impessoais. Além do temor ao espectro do comunismo, os mandantes receavam que após o golpe viesse a surgir um novo caudilho, à maneira do que mostrava a recente história latino-americana. Para evitar isso eles separaram as funções de governantes e membros das forças armadas mediante alguns expedientes: reformaram os militares mais carismáticos; mantiveram a presidência da república como cargo eletivo, ainda que dependente de um colégio eleitoral e sujeita a mandatos com duração estabelecida. A constituição de 1967 concentrou poderes

37 PRZEWORSKI, Adam. Divided we stand? Democracy as a method of processing conflicts. Scandinavian Political Studies, p. 169

38 PRZEWORSKI, Adam. Divided we stand? Democracy as a method of processing conflicts. Scandinavian Political Studies, p. 173

39 PRZEWORSKI, Adam. Divided we stand? Democracy as a method of processing conflicts. Scandinavian Political Studies, p. 178-179

40 ROCHA, Antônio Sérgio. Genealogia da Constituinte: do autoritarismo à democratização. Lua Nova. São Paulo, número 88,2013 , p. 32-33

Disponível em: http://www.cedec.org.br/constituicao-e-processo-constituinte---no88---ano-2013. Acesso em: 23 de junho de 2017 
BENÍTEZ, José Leandro Farias. A Constituição brasileira de 1988 e o conceito de Pacto Constitucional. Revista Eletrônica Direito e Política, Programa de Pós-Graduação Stricto Sensu em Ciência Jurídica da UNIVALI, Itajaí, v.13, n.2, $2^{\circ}$ quadrimestre de 2018. Disponível em: www.univali.br/direitoepolitica - ISSN 1980-7791

no executivo e na União, e os mecanismos de controle sobre os detentores do poder político foram enfraquecidos.

O Brasil começou a marchar para a democratização quando os resultados pretendidos pelos governos militares se tornaram indesejados e imprevistos, ou seja, quando começaram a aparecer riscos e a efetiva mudança da "determinação para a indeterminação do processo"41. Exemplos disso são as derrotas eleitorais que se verificaram a partir de 1974; a crise econômica; a perda da maioria na Câmara em 1992; a campanha pelas eleições diretas; a incapacidade de colocar um presidente em 1984-1985. A lenta, progressiva e irremissível erosão do regime, sua falta de legitimação e a pressão internacional acarretaram a necessidade de democratização, e com ela a feitura de uma nova constituição, que os detentores do poder almejavam que se desse através de um processo constituinte.

Jon Elster notou que a elaboração de constituições tende a ocorrer em ondas. Considerando que as constituições modernas começaram a ser elaboradas no fim do século XVIII, esse autor detectou sete ondas: 1) Entre 1780 e 1791, cujos casos mais conhecidos foram as constituições dos Estados Unidos e da França; 2) A onda produzida em torno das revoluções de 1848 na Europa; 3) Época posterior à I Guerra Mundial, cujo exemplo é a constituição de Weimar; 4) Após a II Guerra Mundial, por ocasião das constituições da Alemanha e Itália; 5) Com a quebra dos regimes coloniais da França e Inglaterra, cujo início se deu nos anos 40 e o pico se deu nos anos 60 ; 6) Com a queda das ditaduras do sul da Europa, na metade dos anos 70: Portugal, Espanha, Grécia; 7) Após a queda do comunismo, em 198942. Talvez o caso do Brasil possa se enquadrar nos efeitos tardios da onda de número 6 , e a redemocratização ter recebido a influência da experiência espanhola, levada a efeito pelos Pactos da Moncloa; mas isto só pode ser afirmado após um estudo específico. O que é característico, segundo Elster, é que as ondas constitucionais se explicam porque elas são sempre feitas no emergir de uma crise

\footnotetext{
41 ARAUJO, Cicero. O processo constituinte brasileiro, a transição e o Poder Constituinte. Lua Nova., p. 357

42 ELSTER, Jon. Forces and mechanisms in the constitution-making process. Duke Law Journal. Durham: número 45, 1995, p. 368. Disponível em: http://scholarship.law.duke.edu/dlj/vol45/iss2/2. Acesso em: 23 de junho de 2017
} 
BENÍTEZ, José Leandro Farias. A Constituição brasileira de 1988 e o conceito de Pacto Constitucional. Revista Eletrônica Direito e Política, Programa de Pós-Graduação Stricto Sensu em Ciência Jurídica da UNIVALI, Itajaí, v.13, n.2, 20 quadrimestre de 2018. Disponível em: www.univali.br/direitoepolitica - ISSN 1980-7791

ou de circunstâncias excepcionais; quer dizer: a ligação entre crises e a feitura de constituições é robusta ${ }^{43}$. Efetivamente, crises são identificadas em todas as ondas acima, como por exemplo a crise econômica experimentada pelos Estados Unidos antes da constituição de $1787^{44}$. No mesmo sentido se manifesta Pasquino: muitas vezes uma constituição é uma manifestação de uma nova ordem, "a declaração de morte de um regime anterior e a trombeta de um novo mundo; uma promessa e uma esperança", mas também simplesmente a carta organizadora de um novo poder governamental ${ }^{45}$.

\subsection{OS DEBATES CONSTITUCIONAIS NA TRANSIÇÃO POLÍTICA}

Com o Ato Institucional número 1 , de 1964, os militares se atribuíram o poder constituinte originário. Logo veio a constituição de 1967 -que se considerou outorgada46 - e em 1969 uma emenda constitucional. Aproximadamente vinte anos depois havia sido gestada uma nova ordem democrática e constitucional, na qual os debates sobre os escombros da ordem cessante passaram a ter grande variedade e vivacidade. Clamava-se pela elaboração de uma nova constituição, e cedo se começou a debater a respeito do tipo de poder constituinte que se delineava. Havia uma corrente que considerava a assembleia constituinte, que seria instalada, plenamente soberana, portanto capaz de sustentar que os parlamentares assumissem o controle político do país. De outro lado havia os que a consideravam derivada, e que os parlamentares deveriam se restringir a elaborar a nova constituição sem interferir nas instituições anteriores à promulgação. Para estes últimos a inexistência de ruptura no processo político desqualificaria a caracterização da assembleia constituinte como originária ${ }^{47}$. Não obstante, entre

43 ELSTER, Jon. Forces and mechanisms in the constitution-making process. Duke Law Journal, p. 370

44 ELSTER, Jon. Forces and mechanisms in the constitution-making process. Duke Law Journal, p. 370

45 PASQUINO, Pasquale. Classifying constitutions: preliminary conceptual analysis. Cardozo Law Review, p. 1010

46 BESTER, Gisela Maria. Cadernos de direito constitucional. Parte I - Teoria constitucional. Porto Alegre: Síntese, 1999, p. 37

47 ROCHA, Antônio Sérgio. Genealogia da Constituinte: do autoritarismo à democratização. Lua Nova, p. 74 
BENÍTEZ, José Leandro Farias. A Constituição brasileira de 1988 e o conceito de Pacto Constitucional. Revista Eletrônica Direito e Política, Programa de Pós-Graduação Stricto Sensu em Ciência Jurídica da UNIVALI, Itajaí, v.13, n.2, 20 quadrimestre de 2018. Disponível em: www.univali.br/direitoepolitica - ISSN 1980-7791

a dualidade tradicional do poder constituinte originário ou do poder constituinte derivado pode-se afirmar, abstraindo das longas -e por vezes erradas- razões dos debates, que se tratou de poder constituinte derivado ou reformador, uma vez que a convocação do congresso constituinte se deu por emenda constitucional ${ }^{48}$. Também havia a divergência se a assembleia constituinte deveria ser exclusiva ou congressual. A opção foi pela segunda hipótese, o que lhe retirou méritos democráticos porque supunha a concomitância do exercício da atividade políticopartidária com a elaboração da nova lei maior. Além disso há que lembrar que um certo número de membros da assembleia não havia sido participado do pleito 1986 porque eleitos em 1982, e não haviam sido afetados pela renovação do senado ${ }^{49}$.

À margem desses e tantos outros debates, duas considerações muito importantes devem ser feitas de modo a se recolher a rica experiência histórica que nos foi oferecida (Ambas são certeiramente apontadas por Araujo.). 1) É difícil e sujeita a deslizes a tarefa de enquadrar diversos fatos políticos dentro de conceitos com grande densidade normativa, como o de poder constituinte, que pode ter origem em desobediência civil generalizada, revolução ou um golpe de estado. O mesmo se pode dizer das diversas continuidades ou descontinuidades institucionais, que podem resultar de uma passagem suave ou abrupta de uma situação política anterior $^{50}$. 2) Independentemente do que teorias constitucionais dissessem, a constituição iria ser feita, de modo que alguns juristas e políticos opinaram que as estratégias a serem levadas e efeito eram mais importantes que o próprio debate conceitual. Tudo isto consolidava a ideia de que as teorias constitucionais não eram capazes então de "abarcar satisfatoriamente os interesses e os valores em jogo"51.

\footnotetext{
48 BESTER, Gisela Maria. Cadernos de direito constitucional. Parte I - Teoria constitucional, p. 84; ROCHA, Antônio Sérgio. Genealogia da Constituinte: do autoritarismo à democratização. Lua Nova, p. 55 37

49 BESTER, Gisela Maria. Cadernos de direito constitucional. Parte I - Teoria constitucional, p.

50 ARAUJO, Cicero. O processo constituinte brasileiro, a transição e o Poder Constituinte. Lua Nova, p. 328

51 ARAUJO, Cicero. O processo constituinte brasileiro, a transição e o Poder Constituinte. Lua Nova., p. 333
} 
BENÍTEZ, José Leandro Farias. A Constituição brasileira de 1988 e o conceito de Pacto Constitucional. Revista Eletrônica Direito e Política, Programa de Pós-Graduação Stricto Sensu em Ciência Jurídica da UNIVALI, Itajaí, v.13, n.2, $2^{\circ}$ quadrimestre de 2018. Disponível em: www.univali.br/direitoepolitica - ISSN 1980-7791

\subsection{PACTO CONSTITUCIONAL, MAS DE QUE TIPO?}

Deve-se indagar primeiramente se a constituição de 1988 foi de base democrática dentro da concepção de Schmitt, pois segundo ele isto só ocorre quando o poder constituinte do povo é exercido do modo exclusivo ${ }^{52}$. Contrariamente, "uma pluralidade de sujeitos do poder constituinte destroçaria a unidade política"53, a qual é requisito para a caracterização de um poder constituinte democrático. Ademais "a doutrina democrática não conhece (...) outra constituição legítima que a que se apoie no poder constituinte do povo"54.

Compreensivelmente o processo constituinte brasileiro teve como protagonista o poder constituinte do soberano, exercido por um governo eleito sem o sufrágio popular direto. Resta então qualificar o fundamento da nossa carta em um pacto constitucional. Porém antes convém fazer algumas considerações desde uma visão da teoria constitucional que Holmes chama de "realista", que aqui pode ser invocada ligeiramente.

O realismo diz que o controle constitucional sobre o poder político surge porque as elites servem aos interesses de indivíduos associados como força social organizada. Uma das forças sociais mais bem organizadas e poderosas é o próprio governo. Para se analisar bem as limitações constitucionais há que se examinarem as vantagens que as elites governantes colhem ao aceitar restrições na sua liberdade de agir. As restrições constitucionais são difíceis de entender se seu propósito é beneficiar o fraco e incapacitar o forte. Mas é mais fácil de entendêlas quando os poderosos rejeitam formas de poder -aparentemente não vantajosas- que Ihes permitem conquistar seus objetivos principais ${ }^{55}$.

\footnotetext{
52 SCHMITT, Carl. Teoría de la constitución, p. 84

53 SCHMITT, Carl. Teoría de la constitución, p. 86

54 SCHMITT, Carl. Teoría de la constitución, p. 111

55 HOLMES, Stephen. Constituições e constitucionalismo. In: ASENSI, Felipe Dutra e PAULA, Daniel Giotti de (organizadores). Tratado de Direito Constitucional: constituição no século XXI. Volume 2. Rio de Janeiro: Elsevier, 2014, p. 580 e 606
} 
BENÍTEZ, José Leandro Farias. A Constituição brasileira de 1988 e o conceito de Pacto Constitucional. Revista Eletrônica Direito e Política, Programa de Pós-Graduação Stricto Sensu em Ciência Jurídica da UNIVALI, Itajaí, v.13, n.2, $2^{\circ}$ quadrimestre de 2018. Disponível em: www.univali.br/direitoepolitica - ISSN 1980-7791

As constituições nunca são imparciais; elas nunca tratam o poderoso e o fraco de igual maneira ${ }^{56}$. Para quem acompanhou a história da redemocratização nacional há um sem-fim de razões para afirmar o caráter preponderantemente não popular da constituição federal de 1988 (aqui cabe repetir a já mencionada terminologia de Waldron: constitucionalismo popular ou democrático). Entre as forças políticas atuantes e altissonantes na época são mencionáveis os proprietários de terras, banqueiros, membros do Poder Judiciário e do Ministério Público, por não falar na própria classe política. Esta última, como é sabido, era integrada por um presidente da República que atuou e interferiu na assembleia constituinte ${ }^{57}$.

Também é sabido que a abertura política e o processo de transição democrática foram rigorosamente controlados ${ }^{58}$. De certo modo não são muito estranhas certas decisões políticas daquela etapa da história se se tem presente o que diz Holmes: governos sempre foram constituídos para a defesa coletiva e a dominação hierárquica. Grupos sociais dominantes concordam em impor restrições a seus membros para sustentar, com mínimo de força, os seus privilégios ao longo do tempo e mobilizar a cooperação das classes baixas para um empreendimento coletivo, especialmente a cobrança de tributos e a guerra ${ }^{59}$.

Carl Schmitt diz que uma constituição é legítima -isto é: reconhecida como situação de fato e como ordenação jurídica- quando a autoridade do poder constituinte sobre o qual descansa é reconhecido ${ }^{60}$. Pode-se dizer que, com base na duplicidade de titulares do poder constituinte intervenientes na transição democrática -o soberano e o povo-, não houve o reconhecimento político pleno de parte a parte: do povo ao governo da época, por sua origem fracamente

\footnotetext{
56 HOLMES, Stephen. Constituições e constitucionalismo. In: ASENSI, Felipe Dutra e PAULA, Daniel Giotti de (organizadores). Tratado de Direito Constitucional: constituição no século XXI, p. 605

57 ROCHA, Antônio Sérgio. Genealogia da Constituinte: do autoritarismo à democratização. Lua Nova, p. 71

58 ARAUJO, Cicero. O processo constituinte brasileiro, a transição e o Poder Constituinte. Lua Nova., p. 355

59 HOLMES, Stephen. Constituições e constitucionalismo. In: ASENSI, Felipe Dutra e PAULA, Daniel Giotti de (organizadores). Tratado de Direito Constitucional: constituição no século XXI, p. 579

60 SCHMITT, Carl. Teoría de la constitución, p. 104
} 
BENÍTEZ, José Leandro Farias. A Constituição brasileira de 1988 e o conceito de Pacto Constitucional. Revista Eletrônica Direito e Política, Programa de Pós-Graduação Stricto Sensu em Ciência Jurídica da UNIVALI, Itajaí, v.13, n.2, 20 quadrimestre de 2018. Disponível em: www.univali.br/direitoepolitica - ISSN 1980-7791

democrática; e dos governos ao povo, cujo futuro era perigosamente incerto para as elites, envolvidas desde então no afastamento das ameaças da esquerda.

A duplicidade do poder constituinte naquela época evidencia que houve a formação de um pacto constitucional. Trata-se da já explicada posição de Schmitt, que diz que uma convenção constitucional supõe a existência de várias unidades políticas ${ }^{61}$. Embora a distinção entre pacto constitucional autêntico e não autêntico fique entre o sutil e o difícil, há alguns argumentos para inclinar-se em um sentido e não outro.

No processo de democratização no Brasil o princípio monárquico contido na figura do soberano cessante foi expelido como se se tratasse de um trabalho de parto, isto pelo caráter rigidamente controlado das concessões democráticas do novel governo civil, em dose de conta-gotas. É óbvio que não se tratou de uma constituição outorgada, mas sim de uma constituição concedida, possível. Devese frisar, com base na outra vez arguta percepção de Araujo, que, na disputa pelo posto de príncipe, um dos postulantes sempre foi uma oposição consentida: o MDB/PMDB, que era oposição ao regime, mas também a oposição do regime. Semelhante "dupla personalidade" nunca costuma ser fácil de conciliar.

A iniciativa de embandeirar a democratização e todos os seus desdobramentos se deu porque o PMDB, apesar de vitorioso na eleição de 1982, se mostrava inseguro quanto a ter força para disputar a eleição presidencial que se avizinhava62, comportamento este que pareceu perdurar em anos posteriores.

Também é possível afirmar que, apesar das divergências, os partidos do regime (no princípio MDB e ARENA) formavam uma aliança tácita. Isto porque de um lado e de outro havia integrantes que pretendiam disputar a presidência da República. Já o governo queria impulsionar a abertura, e por isso teria que dar poder aos partidos, de modo a torná-los interlocutores relevantes na negociação das

${ }^{61}$ SCHMITT, Carl. Teoría de la constitución, p. 82

62 ARAUJO, Cicero. O processo constituinte brasileiro, a transição e o Poder Constituinte. Lua Nova., p. 354 
BENÍTEZ, José Leandro Farias. A Constituição brasileira de 1988 e o conceito de Pacto Constitucional. Revista Eletrônica Direito e Política, Programa de Pós-Graduação Stricto Sensu em Ciência Jurídica da UNIVALI, Itajaí, v.13, n.2, 20 quadrimestre de 2018. Disponível em: www.univali.br/direitoepolitica - ISSN 1980-7791

reformas constitucionais necessárias ao implemento dos programas do governo ${ }^{63}$. Então nasceu a ideia de restabelecer as eleições diretas, e mais tarde a de criar uma assembleia constituinte. Embora a mudança da constituição fosse necessária, a forma de empreendê-la foi uma solução de meio termo para evitar que o PMDB, na hipótese de chegar ao governo, tivesse que buscar saídas muito diversas das que pretendiam os outros integrantes da frente, oriundos do regime anterior ${ }^{64}$.

Como foi exposto acima, entre as várias características do pacto social autêntico estão: a) a ocorrência de um pacto federal; b) um pacto livre; c) vontades coincidentes dos representantes do poder constituinte; d) mudança de status. Por tudo o examinado, pode-se afirmar que não ocorreu no Brasil a formação de um novo pacto federal que colocasse em novo patamar os atores políticos. A história posterior do Brasil, a começar pela eleição presidencial de 1989, parece demonstrar que persistiram as antigas distâncias que outrora separavam o monarca e o povo. O pacto formado no Brasil não foi totalmente livre, dado o caráter medido das concessões democráticas e a índole de um regime que ainda pretendia tornar-se verdadeiramente democrático.

As vontades políticas não convergiram no princípio e não chegaram a formar uma nova unidade. O equilíbrio final a que se chegou só foi possível pela necessidade prática de atingir um resultado possível. Não houve mudança de status entre os protagonistas do poder constituinte: as camadas populares desde então continuam subalternas e esperam a efetivação ou a garantia de direitos sociais e políticos. Portanto houve um pacto constitucional sim, mas um pacto constitucional não autêntico ou dilatório. Na tipologia oferecida por Pasquino, que distingue: a) constituições elaboradas por elites transformadoras; de b) constituições que incorporam convenções escritas já estabelecidas, há razões para pensar que o que

\footnotetext{
63 ARAUJO, Cicero. O processo constituinte brasileiro, a transição e o Poder Constituinte. Lua Nova, p. 354

64 ARAUJO, Cicero. O processo constituinte brasileiro, a transição e o Poder Constituinte. Lua Nova., p. 362 e 365
} 
BENÍTEZ, José Leandro Farias. A Constituição brasileira de 1988 e o conceito de Pacto Constitucional. Revista Eletrônica Direito e Política, Programa de Pós-Graduação Stricto Sensu em Ciência Jurídica da UNIVALI, Itajaí, v.13, n.2, $2^{\circ}$ quadrimestre de 2018. Disponível em: www.univali.br/direitoepolitica - ISSN 1980-7791

ocorreu no Brasil pende para a primeira dessas alternativas, ou seja: tivemos um pacto com forte predomínio de uma elite ${ }^{65}$.

\section{CONSIDERAÇÕES FINAIS}

Apesar da maioria conservadora no processo constituinte, há quem sustente que no final a constituição brasileira ficou progressista. Não há de ser incorreta essa opinião, mas o que se buscou neste artigo foi responder à questão de se a constituição brasileira de 1988 correspondeu àquilo que Carl Schmitt considerou como pacto constitucional. A hipótese sobre a qual se trabalhou, e que considera comprovada, é a de que efetivamente o processo constitucional na redemocratização nacional teve origem em um pacto constitucional, porém um pacto não autêntico ou dilatório, que é aquele em que se adia a admissão do poder constituinte do povo, o único verdadeiramente democrático na concepção desse autor. Para verificar essa hipótese foi necessário consolidar uma série de hipóteses preliminares, que são listadas a seguir. 1) Não se confundem contrato social com pacto constitucional; 2) O conceito de pacto constitucional se assenta no conceito de poder constituinte; 3) O poder constituinte é uma unidade política concreta; 4) Só existem dois titulares do poder constituinte: o povo na democracia, e o monarca na monarquia autêntica; 5) O pacto constitucional requer a interveniência de pelo menos duas unidades políticas; 6) O pacto constitucional autêntico supõe duas partes, cada uma sendo sujeito de um poder constituinte. Ele é um pacto federal, livre, com vontades claramente manifestadas pelos integrantes, e é um pacto de status; 7) O pacto constitucional não autêntico é aquele que não contém alguma das características acima; 8) A constituição brasileira não se fundou exclusivamente no poder constituinte do povo.

\section{REFERÊNCIAS DAS FONTES CITADAS}

ARAUJO, Cicero. O processo constituinte brasileiro, a transição e o Poder Constituinte. Lua Nova. São Paulo, número 88, 2013, p. 372-380. Disponível em: http://www.cedec.org.br/constituicao-e-processo-constituinte---no88---ano2013. Acesso em: 23 de junho de 2017

65 PASQUINO, Pasquale. Classifying constitutions: preliminary conceptual analysis. Cardozo Law Review, p. 1004 
BENÍTEZ, José Leandro Farias. A Constituição brasileira de 1988 e o conceito de Pacto Constitucional. Revista Eletrônica Direito e Política, Programa de Pós-Graduação Stricto Sensu em Ciência Jurídica da UNIVALI, Itajaí, v.13, n.2, $2^{\circ}$ quadrimestre de 2018. Disponível em: www.univali.br/direitoepolitica - ISSN 1980-7791

BESTER, Gisela Maria. Cadernos de direito constitucional. Parte I - Teoria constitucional. Porto Alegre: Síntese, 1999

COSTA GONÇALVES, Cláudia Maria da. Pacto constitucional e welfare state: anotações de sociologia constitucional brasileira. Revista de Políticas Públicas. São Luís: volume 10, número 1, páginas 91-107, janeiro-junho 2006. Disponível em:

http://www.periodicoseletronicos.ufma.br/index.php/rppublica/article/view/3794 /1893. Acesso em: 23 de junho de 2017

DI TELLA, Torcuato (organizador). Diccionario de ciencias sociales y políticas. Buenos Aires: Emecé, 2001

ELSTER, Jon. Forces and mechanisms in the constitution-making process. Duke Law Journal. Durham: número 45, 1995, p. 364-396. Disponível em: http://scholarship.law.duke.edu/dlj/vol45/iss2/2. Acesso em: 23 de junho de 2017

HOLMES, Stephen. Constituições e constitucionalismo. In: ASENSI, Felipe Dutra e PAULA, Daniel Giotti de (organizadores). Tratado de Direito Constitucional: constituição no século XXI. Volume 2. Rio de Janeiro: Elsevier, 2014, p. 577-608

HOLMES, Stephen. El precompromiso y la paradoja de la democracia. In: ELSTER, Jon e SLAGSTAD, Rune (organizadores). Constitucionalismo y democracia. México: Fondo de Cultura Económica, 1999, p. 217-262

IDUARTE, Marta Morineau. Diccionario de derecho romano. México: Oxford University, 2006

LASSALLE, Ferdinand. O que é uma constituição política. São Paulo: Global, 1987

PASQUINO, Pasquale. Classifying constitutions: preliminary conceptual analysis. Cardozo Law Review. New York: volume 34, número 3, p. 999-1019, fevereiro 2013. Disponível em: http://www.cardozolawreview.com/content/343/PASQUINO.34.3.pdf. Acesso em: 23 de junho de 2017

PRZEWORSKI, Adam. Divided we stand? Democracy as a method of processing conflicts. Scandinavian Political Studies. United Kingdom: volume 34, número 2, 2011, p. 168-182. Disponível em: https://onlinelibrary.wiley.com/doi/pdf/10.1111/j.1467-9477.2011.00265.x Acesso em: 23 de junho de 2017

ROCHA, Antônio Sérgio. Genealogia da Constituinte: do autoritarismo à democratização. Lua Nova. São Paulo, número 88, 2013, p. 29-87. Disponível em: http://www.cedec.org.br/constituicao-e-processo-constituinte---no88---ano2013. Acesso em: 23 de junho de 2017

ROUSSEAU, Jean-Jacques. O contrato social. Princípios do direito político. São Paulo: Martins Fontes, 1999

SCHMITT, Carl. Teoría de la constitución. Tradução de Francisco Ayala. Madrid: Alianza, 1996 
BENÍTEZ, José Leandro Farias. A Constituição brasileira de 1988 e o conceito de Pacto Constitucional. Revista Eletrônica Direito e Política, Programa de Pós-Graduação Stricto Sensu em Ciência Jurídica da UNIVALI, Itajaí, v.13, n.2, $2^{\circ}$ quadrimestre de 2018. Disponível em: www.univali.br/direitoepolitica - ISSN 1980-7791

UNITED STATES. Text of the Massachusetts Constitution. Disponível em: http://www.john-adams-heritage.com/text-of-the-massachusetts-constitution/. Acesso em: 23 de junho de 2017

WALDRON, Jeremy. Constitutionalism: a skeptical view. Public \& Legal Theory Research Paper Series. New York: número 10-87, 2012, 46 p. Disponível em: https://papers.ssrn.com/sol3/papers.cfm?abstract_id=1722771. Acesso em: 23 de junho de 2017

Recebido em: 06/07/2018

Aprovado em: 20/07/2018 